\title{
Effect of Temperature on the Deformation Behavior of Copper Nickel Alloys under Sliding
}

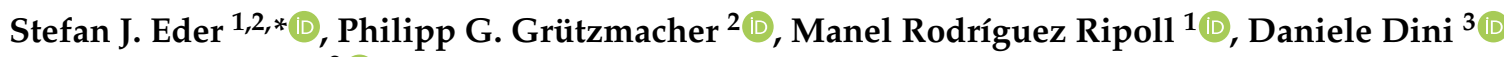 \\ and Carsten Gachot ${ }^{2}$ (I)
}

Citation: Eder, S.J.; Grützmacher, P.G.; Rodríguez Ripoll, M.; Dini, D.; Gachot, C. Effect of Temperature on the Deformation Behavior of Copper Nickel Alloys under Sliding. Materials 2021, 14, 60. https://dx.doi.org/10.3390/ ma14010060

Received: 9 December 2020 Accepted: 22 December 2020 Published: 25 December 2020

Publisher's Note: MDPI stays neutral with regard to jurisdictional claims in published maps and institutional affiliations.

Copyright: (C) 2020 by the authors. Licensee MDPI, Basel, Switzerland. This article is an open access article distributed under the terms and conditions of the Creative Commons Attribution (CC BY) license (https:/ / creativecommons.org/ licenses/by/4.0/).
1 AC2T Research GmbH, Viktor-Kaplan-Straße 2/C, 2700 Wiener Neustadt, Austria; ripoll@ac2t.at

2 Institute for Engineering Design and Product Development, TU Wien, Lehárgasse 6-Objekt 7, 1060 Vienna, Austria; philipp.gruetzmacher@tuwien.ac.at (P.G.G.); carsten.gachot@tuwien.ac.at (C.G.)

3 Department of Mechanical Engineering, Imperial College London, South Kensington Campus, Exhibition Road, London SW7 2AZ, UK; d.dini@imperial.ac.uk

* Correspondence: stefan.j.eder@tuwien.ac.at

\begin{abstract}
The microstructural evolution in the near-surface regions of a dry sliding interface has considerable influence on its tribological behavior and is driven mainly by mechanical energy and heat. In this work, we use large-scale molecular dynamics simulations to study the effect of temperature on the deformation response of FCC CuNi alloys of several compositions under various normal pressures. The microstructural evolution below the surface, marked by mechanisms spanning grain refinement, grain coarsening, twinning, and shear layer formation, is discussed in depth. The observed results are complemented by a rigorous analysis of the dislocation activity near the sliding interface. Moreover, we define key quantities corresponding to deformation mechanisms and analyze the time-independent differences between $300 \mathrm{~K}$ and $600 \mathrm{~K}$ for all simulated compositions and normal pressures. Raising the Ni content or reducing the temperature increases the energy barrier to activate dislocation activity or promote plasticity overall, thus increasing the threshold stress required for the transition to the next deformation regime. Repeated distillation of our quantitative analysis and successive elimination of spatial and time dimensions from the data allows us to produce a 3D map of the dominating deformation mechanism regimes for $\mathrm{CuNi}$ alloys as a function of composition, normal pressure, and homologous temperature.
\end{abstract}

Keywords: microstructure; plastic deformation; FCC alloys; molecular dynamics; sliding contact

\section{Introduction}

The mechanical behavior of a material is greatly influenced by its microstructure. In terms of grain size, for example, there seems to be an optimum size representing the transition from dislocation dominated plasticity to grain boundary (GB) sliding, thus maximizing both strength and hardness [1,2]. Naturally, the tribological properties of a material under dry sliding are also defined by its microstructure [1,3]. In literature, numerous studies can be found that report beneficial effects in terms of tribological performance when decreasing the grain size [2-5]. However, tribological processes beneath a sliding contact are highly dynamic, resulting in significant changes to the microstructure as a result of tribological loading [6]. For instance, it has been frequently shown that nanocrystalline regions close to a tribologically loaded contact exhibit grain coarsening, whereas coarse-grained materials usually undergo grain refinement in the near-surface zones [3,6-8]. In this context, it has been demonstrated that the grain size tends to an equilibrium value, which is linked to energy minimization and depends on the contact conditions such as contact stress [3,9]. In the course of sliding, the tribological properties change, sometimes drastically, until the system is at equilibrium and a "stable" configuration is formed for the given sliding conditions, marking the end of running-in, i.e., the initial period when surface interactions cause drastic transient changes to the material and topography of contacting 
bodies. Therefore, the tribological properties not only depend on the initial microstructure, but largely on the modified microstructure in the near-surface zones.

As demands in terms of energy efficiency and reliability of machine elements are becoming increasingly stringent [10], it is inevitable to include a materials scientific perspective in the investigation of surfaces subjected to friction, focusing not only on surface finishing (e.g., grinding, honing, or surface texturing) [11], but also the microstructural evolution. If the prevailing mechanisms that are responsible for the microstructural changes in the near-surface zones are fundamentally understood, this can contribute to tailoring materials with improved performance and extended service life. Argibay et al. reported low coefficients of friction $(\mu<0.5)$ for pure $\mathrm{Cu}$ and Au tribopairs in nonlubricated sliding, which can be traced back to a certain microstructure developing if stress and temperature are adequate [3]. However, if the operating conditions are less favorable, the microstructure in the near-surface zones is characterized by coarse grains and immediate high friction $(\mu>1.0)$. Thus, controlling the microstructure in the zones close to the frictional interface is highly important for achieving low friction and wear.

In addition to the mechanical energy introduced into the system, heat is the other main driving force for microstructural change, usually resulting in grain growth, and thus possibly high friction. This heat can be introduced into the system either externally (i.e., operating temperature), or it can be generated by the sliding process itself. Operating conditions for machine components have increasingly become more severe in the last decades [12]; for example, in the automotive [13,14], aircraft [15], or manufacturing industry [16], the operating temperatures have increased, thus also more strongly affecting the microstructural evolution of the involved surfaces.

As the processes in a tribological contact are highly dynamic, experimental investigation of the governing mechanisms is highly challenging, even more so at elevated temperature where both plastic deformation and the introduced thermal energy can potentially affect the resulting microstructure. At lower temperatures, plasticity is governed by dislocation glide, a process that has little dependence on temperature. Conversely, at elevated temperatures, dislocation climb starts to dominate due to its stronger dependence on temperature. The increasing dominance of dislocation climb, aided by increased lattice diffusion at high temperatures, results in a significant softening of metals at homologous temperatures above $0.4 T_{m}$ [17]. The reason for this steep hardness drop is the onset of creep, a rate-dependent plasticity mechanism that arises due to dislocation climb [18]. Climbing adds a new degree of freedom to dislocations, so that once a gliding dislocation is stopped by an obstacle, it may overcome it by climbing, resulting in macroscopic softening. The situation is further complicated as plastic deformation and temperature show interdependences: for example, the driving force for temperature-induced grain growth will increase with ongoing grain refinement through plastic deformation. For combinations of two or more chemical elements in solid solution, the high-temperature plastic behavior becomes even more complex. Properties such as the lattice parameter, stacking fault energy, and melting point are all affected by the additional elements present in a solid solution. A further consequence is that solute atoms can interact with dislocations present in the crystal lattice, thus retarding dislocation climbing and making the material less prone to creep. This results in reduced thermal softening due to the higher constraints imposed to plastic deformation.

Over the past decades, computer simulations have become an important tool to shed light on complex phenomena and to identify the associated mechanisms. In particular, molecular dynamics (MD) simulations are intrinsically suitable to study nanoscopic aspects of microstructure evolution. It was already demonstrated in the early 2000s that plastic deformation processes like dislocation generation can be reproduced with polycrystalline MD models [19-21], which have the advantage that they do not require parameters such as activation energies for structural changes like grain growth, or the assumption of constitutive material laws as in continuum mechanics [22]. High-performance computing nowadays allows us to analyze the dynamics of systems consisting of tens to hundreds 
millions of atoms over periods of some $10 \mathrm{~ns}$, evolving them into tools for solving surface and production engineering problems $[23,24]$.

Current literature on MD simulations provides tremendous insight into the material behavior on the nanoscale and the microstructural evolution during plastic deformation $[1,25]$. In tribological contacts, the substrate is usually only in contact at the asperity level, assuming that we focus on dry or boundary-lubricated situations [26]. The substrate is therefore repeatedly exposed to non-homogeneous pressure distributions, with time-variable stress conditions applying below the contact regions as the asperities of the counterbody pass. As tribological properties are strongly influenced by the material properties near the sliding interface, this is of great relevance for the friction and wear performance of a material [7]. Additionally, it has been shown that microstructural changes in a material subjected to sliding occur at the very beginning of these interfacial processes (i.e., running-in), even after one single pass of the counterbody, making the time span observable with MD reasonable to study such phenomena $[7,27]$. The issues of experimental investigation of (subtle) microstrucutral changes as well as the necessity to study the microstructural evolution by methods that feature high temporal and lateral evolution, make MD a perfect tool to study such phenomena.

In recent work, the authors have derived a deformation mechanism map for CuNi alloys at room temperature from MD simulations [23]. CuNi alloys have numerous applications such as in shipbuilding, offshore oil production, power plants [28], electrical sliding contacts [29], and they are used in a similar fashion as $\mathrm{CuAl}$ coatings in tribological interfaces of jet engine compressors [15]. CuNi is an ideal alloy system in which both constituents form an isomorphous system without phase precipitation, where the stacking fault energy varies by a factor of three between pure $\mathrm{Cu}$ and $\mathrm{Ni}$, and a fast and reliable force field exists that allows a treatment using MD [30]. For the correctness and transferability of the deformation mechanism map, it is important to achieve temperature gradients that realistically reflect the macroscopic heat conductivity of the sample [31]. Due to the small size of the modeled systems (layer thickness of $40 \mathrm{~nm}$ ), they can only self-consistently increase their temperature due to friction by $100-150 \mathrm{~K}$ at the surface. For this work, we have therefore produced an additional MD data set (corresponding to 4 million CPU-h of computation time on the VSC4 HPC cluster with 2.7 PFlop/s) for CuNi alloys sliding at a bulk temperature of $600 \mathrm{~K}$ that allows us to study the important influence of temperature on the occurring microstructural mechanisms.

In this paper, we first give an overview of the considered alloys, our simulation approach, the adopted model, and the relevant parameters. We then discuss the resulting data at the example of two representative alloys at two distinct temperatures, allowing us to go into the necessary detail for a materials scientific interpretation. This is followed by a quantitative composition-, pressure-, and temperature-dependent analysis of the entire dataset. A rigorous analysis of the dislocation activity near the sliding interface sheds light on the differences between mechanically versus thermally induced processes. We conclude by presenting and discussing a three-dimensional map of deformation mechanism regimes as a function of applied pressure, Ni content, and temperature.

\section{Materials and Methods}

Our simulations were performed using the open-source MD code LAMMPS [32], which has become the de-facto standard for meshless simulations in academic tribological research. The polycrystalline MD model measures $85 \times 85 \times 40 \mathrm{~nm}^{3}$, contains approximately 25 million atoms, and was prepared as explained in [33,34]. Boundary constraints were applied to the lower $3 \AA$ of the model, where a "sacrificial layer" of $\sim 10$ nm grains was attached to the "working layer" of $\sim 40 \mathrm{~nm}$ grains so none of the occurring mechanisms would be externally constrained. Interactions within the fcc $\mathrm{CuNiX}$ samples, where $X$ is the atomic percentage of $\mathrm{Ni}(0 \%, 5 \%, 25 \%, 60 \%$, and $100 \%)$, are governed by an embedded atom potential from [30]. All alloy systems were initially prepared by heat treatment and cooling to $300 \mathrm{~K}$ as described in [23]. The systems were subsequently linearly heated to 
$600 \mathrm{~K}$ over $200 \mathrm{ps}$ and then kept at $600 \mathrm{~K}$ for another 200 ps before sliding. $600 \mathrm{~K}$ correspond to $0.44 T_{m}$ for pure $\mathrm{Cu}$ and $0.35 T_{m}$ for pure $\mathrm{Ni}$.

The counterbody is a bcc $\mathrm{Fe}(100)$ monocrystal with a Gaussian root-mean square surface roughness of $0.5 \mathrm{~nm}$, a fractal dimension of 2.186, and a characteristic lateral asperity extent of $33 \mathrm{~nm}$, which are values similar to what has previously been used in literature [35]. We reduced its thickness to several monolayers and kept it rigid to have most of the computational resources available for the simulation of the microstructural evolution of the polycrystalline CuNi sample, which implies that the counterbody is much harder than the sample. Lennard-Jones potentials controlled the interactions between the counterbody and the sample, effectively implying a third body, with the global energy parameter $\varepsilon=0.095 \mathrm{eV}$ obtained as described in [36], while $\sigma_{\mathrm{Fe}-\mathrm{Cu}}=0.224 \mathrm{~nm}$ and $\sigma_{\mathrm{Fe}-\mathrm{Ni}}=0.221 \mathrm{~nm}$ were calculated from interactomic first-neighbor distances using the Lorentz-Berthelot mixing rules.

The counterbody was moved across the surface of the sample at a sliding velocity of $v_{\mathrm{x}}=80 \mathrm{~m} / \mathrm{s}$ and a small orthogonal component $v_{\mathrm{y}}=9 \mathrm{~m} / \mathrm{s}$ to prevent roughness features from coming into repeated contact with their own sliding marks. During the simulation runs, the normal pressure $\sigma_{z}$ on the sample was kept constant during sliding at the values listed in Table 1 for a simulation time of $7 \mathrm{~ns}$.

Table 1. Considered alloys (named according to their atomic Ni content), Ni content by weight, intrinsic stacking fault energy $\gamma_{\text {isf }}$ (taken and interpolated from [37]), 0.4 times the melting temperature $T_{m}$, and the normal pressure $\sigma_{z}$ ranges applied in our simulations.

\begin{tabular}{cccccc}
\hline Alloy & $\mathbf{C u}$ & $\mathbf{C u N i 5}$ & $\mathbf{C u N i 2 5}$ & $\mathbf{C u N i 6 0}$ & $\mathbf{N i}$ \\
\hline $\mathrm{wt} \% \mathrm{Ni}$ & 0 & 5 & 24 & 58 & 100 \\
$\gamma_{i s f}\left(\mathrm{~mJ} / \mathrm{m}^{2}\right)$ & 47 & 54 & 79 & 106 & 153 \\
$0.4 \cdot T_{m}(\mathrm{~K})$ & 543 & 551 & 580 & 632 & 691 \\
$\sigma_{z}$ at $300 \mathrm{~K}(\mathrm{GPa})$ & $0.1-0.5$ & $0.2-1.3$ & $0.3-1.6$ & $0.5-1.7$ & $0.5-2.7$ \\
$\sigma_{z}$ at $600 \mathrm{~K}(\mathrm{GPa})$ & $0.05-0.4$ & $0.1-0.8$ & $0.2-0.9$ & $0.5-1.5$ & $0.6-2.1$ \\
\hline
\end{tabular}

A Langevin thermostat with a time constant of 0.5 ps acted on all the non-rigid sample atoms to drain away the frictional heat. This implies that the phonons in the system are coupled to the electrons, which act as a heat bath to mimic the electronic contribution to the thermal conductivity in a metal [31]. The thermostat acts only perpendicular to the directions of sliding and normal pressure in order not to interfere with these external constraints.

The computational tomographs of the polycrystalline $\mathrm{CuNi}$ sample shown and discussed throughout this work are colored according to grain orientations as in electron backscatter diffraction (EBSD), using the inverse pole figure (IPF) coloring standard. The orientations were calculated using the polyhedral template matching modifyer [38] as implemented in the visualization software OVITO [39], and the EBSD colors were produced using the MTEX toolbox [40,41] for Matlab. Dislocation analysis (DXA) was also carried out using OVITO [42].

Grain refinement/growth and twinning were quantified via common neighbor analysis (CNA) [43] with a neighborhood cutoff radius of $0.3086 \mathrm{~nm}$ for all systems containing $\mathrm{Cu}$, and $0.3005 \mathrm{~nm}$ for pure Ni. CNA itself cannot distinguish between grain boundaries, defects, and surfaces on one hand, as well as between twin boundaries, stacking faults, and Shockley partials on the other. To keep our nomenclature simple, we refer only to grain boundary (GB) and twin boundary (TB) atom fractions in this work. The depth- and time-resolved evolution of the GB and TB atom fractions was produced by space-averaging the quantity of interest over lateral layers with a thickness of $1 \mathrm{~nm}$ (corresponding to approximately $6 \times 10^{5}$ atoms).

As detailed further in Ref. [44], atomic advection velocities were obtained by calculating the distance between the positions of an atom at two time steps that are 40 ps apart and associating the obtained average velocity with the atomic position exactly between these two time steps. In this fashion, thermal fluctuations are automatically eliminated like when 
using a low-pass filter. By assuming a threshold velocity of $10 \mathrm{~m} / \mathrm{s}$ for the identification of atoms subjected to shearing, the thickness of the shear layer $d_{\text {shear }}$ can be calculated.

\section{Results and Discussion}

A snapshot of the polycrystalline CuNi model after sliding under severe loading conditions is shown on the left side of Figure 1. The top right panel of Figure 1 shows a cuboid volume with a slab thickness of $5 \mathrm{~nm}$ in which the dislocations were analyzed and colored according to type. The section was cut parallel to the surface normal and sliding directions before the sliding process begins, thus it gives an idea of purely temperatureinduced dislocations. The panel on the bottom right shows a tomographic EBSD section of the same region as the dislocation analysis, where the colors correspond to the grain orientation.

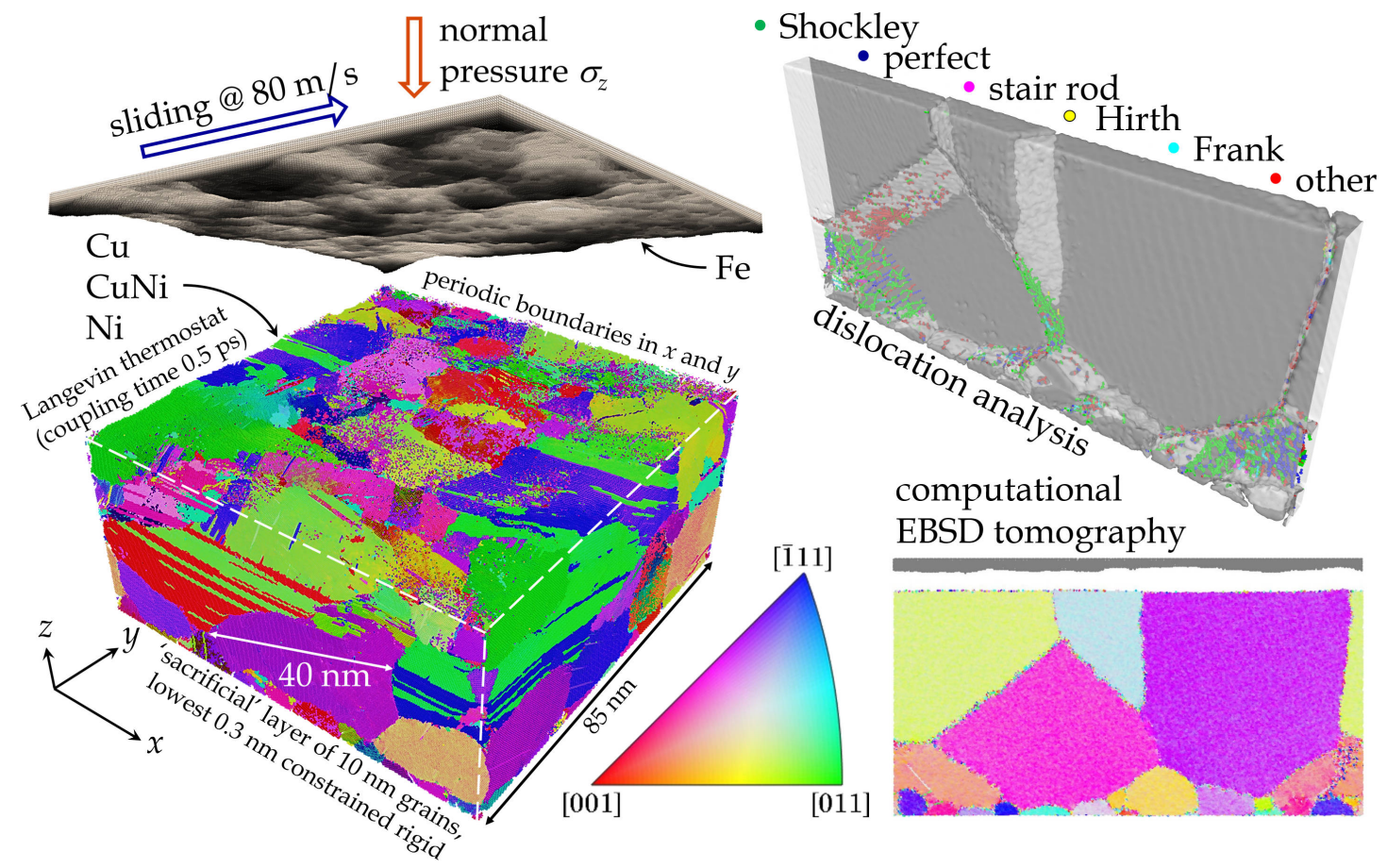

Figure 1. Left: 3D overview of a representative CuNi-Fe tribosystem after sliding, with the interacting bodies separated to yield a clear view of the surface. Different colors in the $\mathrm{CuNi}$ base body represent different crystallographic orientations, gray-scales in the Fe counterbody show its topography. Top right: dislocation analysis of a slice of the initial system before sliding begins, colored by type (see legend). Bottom right: corresponding computational electron backscatter diffraction (EBSD) tomograph (inverse pole figure (IPF) coloring, see legend).

The microstructural evolution as function of composition and temperature for a fixed cross-section of the aggregate under a load of $0.4 \mathrm{GPa}$ are shown in Figure 2 (visualizations of additional time steps can be found in the Supplementary Materials). For Cu at $300 \mathrm{~K}$, the deformation is accommodated by incipient twinning in the large violet grain oriented in (112) direction. Grain refinement starts after $2 \mathrm{~ns}$, but remains limited to the top $20 \mathrm{~nm}$ of the aggregate during the initial stages of sliding. However, up to $5 \mathrm{~ns}$, the degree of grain refinement rises significantly, and at $7 \mathrm{~ns}$ the deformation mechanism slowly switches from grain refinement to stress-induced grain growth, a process which has also been observed experimentally [45]. A rise in temperature to $600 \mathrm{~K}$ results in the appearance of twins well below the surface already after $1 \mathrm{~ns}$ of sliding. Subsequently, the number of observed defects dramatically rises with increasing sliding time. Despite the large number of defects induced by the imparted contact stresses, grain growth sets in after 3 ns and remains prominent afterwards until there are virtually no grain boundaries visible in the discussed cross-section after $7 \mathrm{~ns}$. This can also be traced back to the growing shear layer, which leads to grain rotation and the coalescence of grains [46]. 


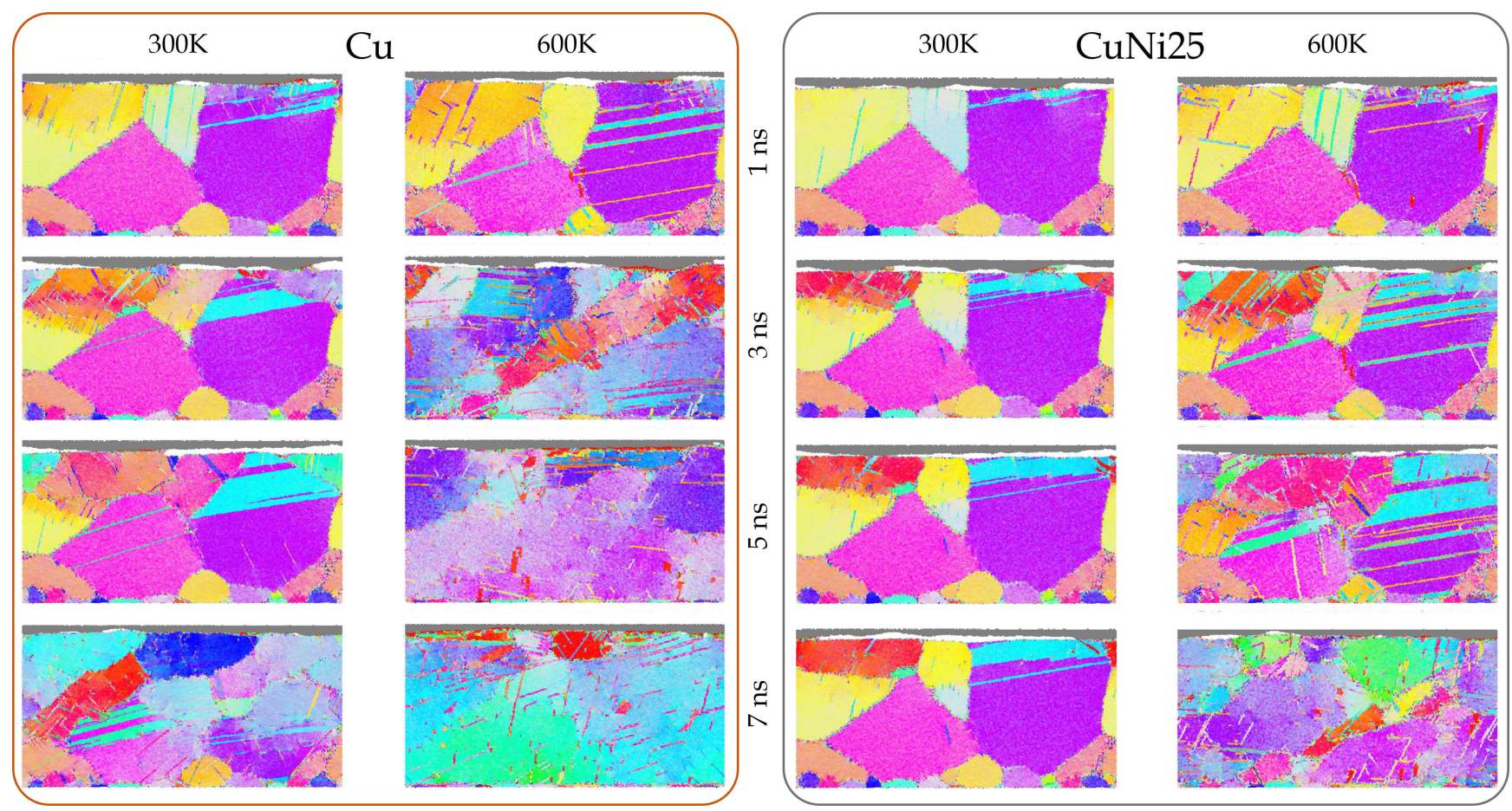

Figure 2. Time evolution of a representative EBSD tomographic section $(85 \mathrm{~nm} \times 40 \mathrm{~nm})$ at constant normal pressure of $0.4 \mathrm{GPa}$. From left to right column: $\mathrm{Cu}$ at $300 \mathrm{~K}, \mathrm{Cu}$ at $600 \mathrm{~K}, \mathrm{CuNi} 25$ at $300 \mathrm{~K}, \mathrm{CuNi} 25$ at $600 \mathrm{~K}$. The EBSD tomograph corresponding to the undeformed system as well as the EBSD color legend are shown in the bottom right of Figure 1.

The initial deformation stages imparted by the counter body during the first $4 \mathrm{~ns}$ of sliding for $\mathrm{CuNi} 25$ at $300 \mathrm{~K}$ are analogous to those observed for pure $\mathrm{Cu}$, but the extent of microstructural changes is to a smaller depth below the surface. For this composition, grain refinement sets in after $2 \mathrm{~ns}$ of sliding but remains limited to the top $10 \mathrm{~nm}$ of the aggregate throughout the entire observation period. Additionally, lattice rotation occurs, which can also result in grain refinement by partial rotation of grains [47]. A rise in temperature to $600 \mathrm{~K}$ again results in more pronounced microstructural changes. Twinning in the (112) oriented violet grain extends deeper below the contact interface, all the way down to the lower boundary of the system. Moreover, twinning can be observed in several other grains such as the neighboring magenta grain oriented in (113). Grain refinement appears at approximately the same time as at $300 \mathrm{~K}$, after $2 \mathrm{~ns}$ of sliding, but it is much more pronounced compared to $300 \mathrm{~K}$. With increasing time, there is an obvious rise in the defect density (in particular starting at $5 \mathrm{~ns}$ ), leading to a microstructure characterized by a high number of dislocations, where incipient temperature- and stress-induced grain growth can be observed. Towards the end of the simulated sliding time, a shear layer starts forming, which leads to the emergence of elongated grains that "lean" in sliding direction.

To further investigate the effect of temperature on the general microstructural behavior of the two different material compositions, the GB and defect fraction increase, the TB fraction, and the mean shear layer thickness are shown in quantitative plots as a function of time in Figure 3. The corresponding results for all simulations conducted at $600 \mathrm{~K}$, including the time- and depth resolved heat maps from which they are distilled, are available in the Supplementary Materials. Regarding the GB and defect fraction, note that only the difference accumulating over the sliding period is depicted to improve comparability by correcting for temperature-dependent baseline differences. Similar trends as shown earlier in the selected cross-sections can be observed in the quantitative results. Pure $\mathrm{Cu}$ has a lower resistance to plastic deformation than $\mathrm{CuNi} 25$ and as a consequence, it generates more GB defects and TBs, while the shear layer extends deeper into the material compared to $\mathrm{CuNi25}$. During the initial $4 \mathrm{~ns}$ of sliding at $300 \mathrm{~K}$, the magnitudes of all these quantities are comparable for both compositions, but afterwards suddenly rise for $\mathrm{Cu}$, while they 
maintain a fairly stable value for CuNi25. As can also be observed in Figure 3, the normal pressure of $0.4 \mathrm{GPa}$ is not sufficient to generate any significant increase in defects or TBs, nor is plastic deformation accompanied by shear for CuNi25 at $300 \mathrm{~K}$. Increasing the temperature to $600 \mathrm{~K}$ with the consequent thermal softening leads to the formation of significant defects, TBs, and a shear layer in both considered compositions. Interestingly, for pure $\mathrm{Cu}$ at $600 \mathrm{~K}$ the maximum in GB fraction, TBs, and shear layer thickness is reached at roughly $3 \mathrm{~ns}$, after which the GB and TB fractions decrease again. As the homologous temperature of this composition is well beyond $0.4 T_{m}$ at $600 \mathrm{~K}$, it exhibits the most intensive thermal softening by promoting dislocation climb. Therefore, the stresses extend the deepest into the surface, leading to a quick establishment of a thick and stable shear layer as well as high GB and TB fractions. The decrease in GB and TB fractions after $3 \mathrm{~ns}$ is in accordance with the observations made in Figure 2, where stress- and shearinduced grain growth can be observed from $3 \mathrm{~ns}$ on. Therefore, pure $\mathrm{Cu}$ ends up with a smaller GB and TB fraction in comparison to $\mathrm{CuNi25}$, despite the steep increase during the first 3 ns of sliding. The decrease in GB fraction in the second half of the simulation of $\mathrm{Cu}$ at $600 \mathrm{~K}$ also leads to a similar GB and defect fraction for pure $\mathrm{Cu}$ after $7 \mathrm{~ns}$ at both temperatures. Note that this seemingly identical behavior between 5.5 and $7 \mathrm{~ns}$ in the quantitative development of $\Delta \mathrm{GB}$ in Figure 3 may be misleading, as the corresponding qualitative behavior is completely different, see Figure 2. Additionally remarkable is the similar twinning behavior of $\mathrm{Cu}$ at $300 \mathrm{~K}$ and $\mathrm{CuNi} 25$ at $600 \mathrm{~K}$, a fact that is thoroughly discussed later on in the dislocation analysis.
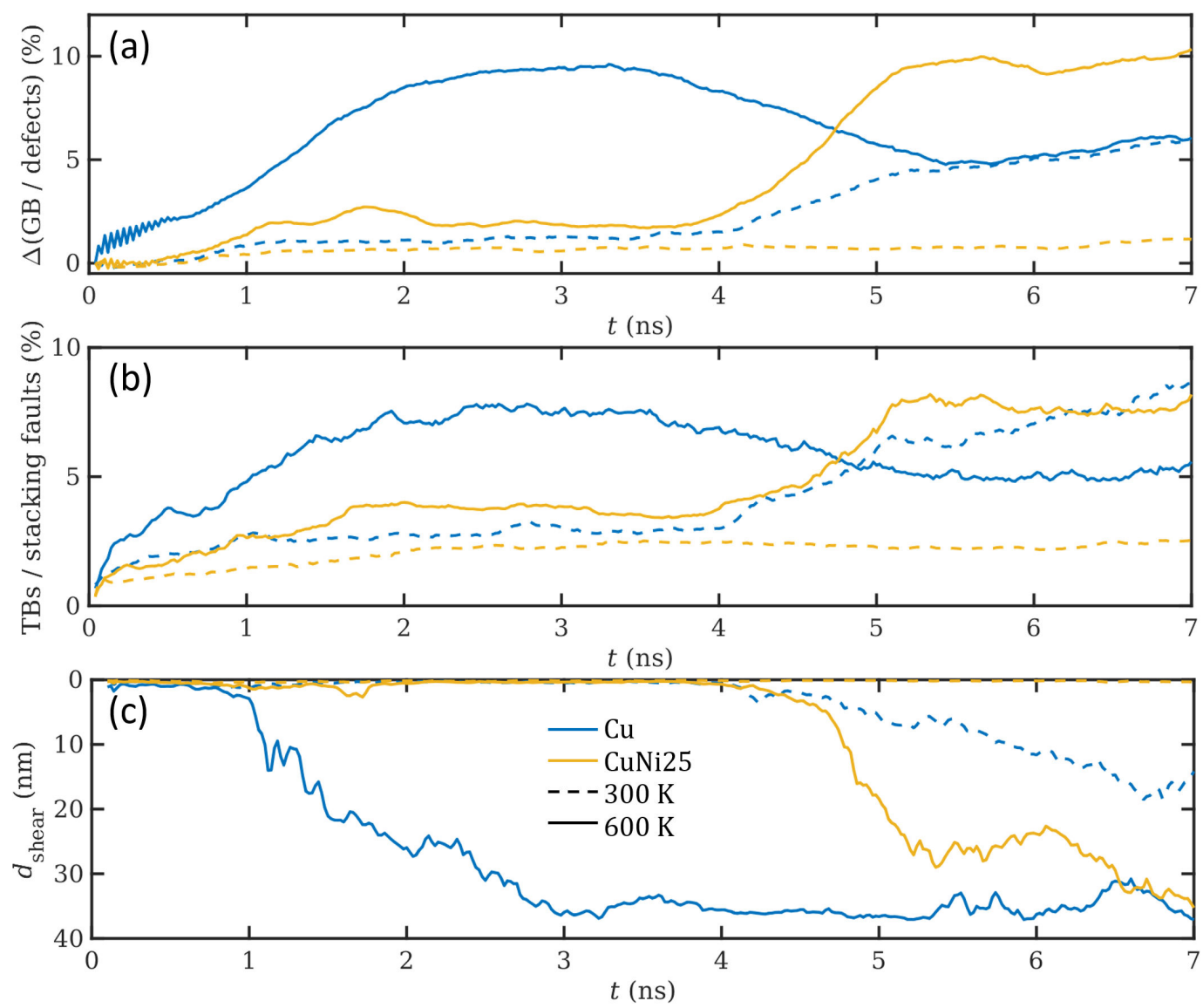

Figure 3. Time development of the excess grain boundary (GB) and defect fraction (a), the twin boundary (TB) and stacking fault fraction (b), and the shear layer thickness (c) of $\mathrm{Cu}$ and CuNi25 at $0.4 \mathrm{GPa}$.

The time-independent effect of temperature on the plastic deformation is demonstrated for all considered compositions in Figure 4, which shows further distilled results of $\Delta \mathrm{GB}, \Delta \mathrm{TB},\left\langle d_{\text {shear }}\right\rangle$, and $s_{\text {trans }}^{(\mathrm{TB})}$ over normal pressure. Higher Ni contents lead to an increase 
in the normal pressure that is necessary to generate a certain number of GB or TB atoms, as was shown in detail in Ref. [23]. When comparing the results for the two different temperatures, the effect of temperature on the GB and TB fraction can be clearly seen. As the intercepts of the fitted trends with the $\sigma_{z}$ axis are the required normal pressures for the initial generation of GB or TB atoms, panels (a) and (b) in Figure 4 show that this pressure is slightly reduced by increasing the temperature to $600 \mathrm{~K}$. With increasing normal pressure, the difference between the two considered temperatures in terms of GB and TB fraction increases. Despite the reduced energy barrier for defect formation with higher temperature, twinning, as a less temperature-sensitive process, also strongly increases with temperature [48]. This leads to the conclusion that it is mainly the extent of the formed GBs and TBs into the depth of the material that is responsible for this increase.

The thickness of the formed shear layer $\left\langle d_{\text {shear }}\right\rangle$ is given as function of the applied stress in Figure 4c. The shear layer consists of all near-surface atoms that move at velocities of $10 \mathrm{~m} / \mathrm{s}$ or faster. For small contact pressures the thickness of the shear layer is negligible, indicating that this deformation mechanism is characteristic of highly loaded sliding contacts. However, for higher pressures, the thickness of the shear layer grows exponentially. In addition to being a function of the contact pressure, the shear layer thickness is also dependent on the alloy composition and temperature. As seen in the figure, and in accordance with the results shown earlier, the formation of the shear layer is delayed for increasing $\mathrm{Ni}$ contents and lower temperatures, as both parameters cause higher resistance to permanent deformation.

The sliding distance $s_{\text {trans }}^{(\mathrm{TB})}$ required for a rapid surge in the number of defect atoms (cf. the yellow curve for CuNi25 at $600 \mathrm{~K}$ between 4 and $5 \mathrm{~ns}$ in Figure 3a,b shows an exponential decrease of the form $s_{0} \exp \left(-\sigma_{z} / \sigma_{\text {trans }}^{(\mathrm{TB})}\right)$, see Figure $4 \mathrm{~d}$, where $\sigma_{\text {trans }}^{(\mathrm{TB})}$ is a compositiondependent characteristic stress value that determines the resistance to plastic deformation. This means that for small applied pressures, the counter body needs to slide for a large distance before causing a fast increase in sub-surface defects, while the distance is dramatically reduced for higher contact pressures. The sliding distance required is also reduced for pure $\mathrm{Cu}$ and lower $\mathrm{Ni}$ contents. In all cases, the presence of $600 \mathrm{~K}$ leads to a reduction in $s_{\text {trans }}^{(\mathrm{TB})}$ ranging from 20 to 50\%. All exponential fits for $s_{\text {trans }}^{(\mathrm{TB})}$ in Figure $4 \mathrm{~d}$, independently of alloy composition or temperature, share the same pre-factor $s_{0}=1800 \mathrm{~nm}$ introduced in Ref. [23] for $300 \mathrm{~K}$, which is more evidence that this quantity, which corresponds to a typical grain boundary length, only depends on the grain structure, morphology, and size of the sample, but not on load, temperature, or composition.

In the graphs for the normal pressure dependence of $\Delta \mathrm{GB}, \Delta \mathrm{TB},\left\langle d_{\text {shear }}\right\rangle$, and $s_{\text {trans }}^{(\mathrm{TB})}$ presented in Figure 4, it seems as if the systems $\mathrm{Cu} @ 300 \mathrm{~K}$ and $\mathrm{CuNi} 25$ at $600 \mathrm{~K}$ behave almost identically. However, it should be noted that the fraction of formed defects and grain boundaries, $\triangle G B$, exhibits considerably different behavior for the same two systems, which may suggest that there are at least two separate mechanisms driving the system response in this respect, one governed by the increase in temperature and one by the increase in stacking fault energy with changes in alloy composition and the addition of Ni. It is particularly interesting to note that the equivalence of the ensemble's response between these two systems, with the effect of temperature and increased stacking fault energy compensating each other for the systems Cu@300 K and CuNi25 at $600 \mathrm{~K}$, may not correspond to the same local evolution of formed defects and grain boundaries.

We will now take a close look at the time resolved dislocation analysis (DXA), presented in Figure 5, where the left box contains the results for $\mathrm{Cu}$ and the right one those for $\mathrm{CuNi} 25$, both at $300 \mathrm{~K}$ and $600 \mathrm{~K}$. The visualizations shown here correspond exactly to the times and locations of the EBSD tomographs from Figure 2, only that the thickness of the slabs was increased to $5 \mathrm{~nm}$ and the slabs slightly rotated so that the dislocation structure obtains more depth. Note that the DXA and EBSD sections before tribological loading are shown on the right side of Figure 1. The dark gray portions of the slabs correspond to grains, and the light gray portions to grain boundaries. Dislocations are shown as little cones colored according to their type, where the dominating color 
green denotes Shockley partials. An extended version of Figure 5 with slabs available for additional time steps can be found in the Supplementary Materials.
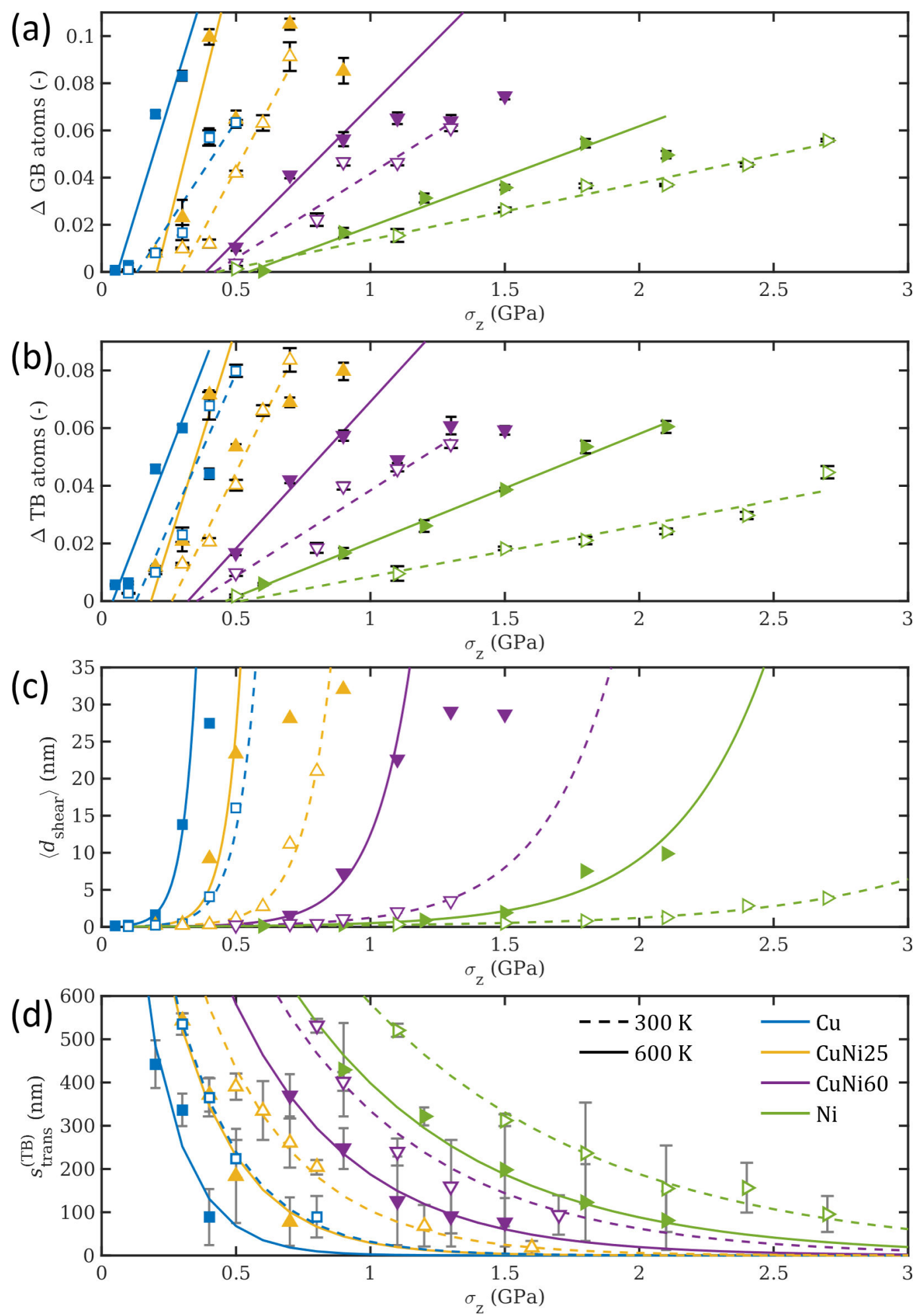

Figure 4. The increase in grain boundary and defect atoms $\Delta \mathrm{GB}(\mathbf{a})$, the increase in twin boundary and stacking fault atoms $\Delta \mathrm{TB}(\mathbf{b})$, the mean shear layer thickness $\left\langle d_{\text {shear }}\right\rangle$ (c), and the twinning transition sliding length $s_{\text {trans }}^{(\mathrm{TB})}$ (d) over the normal pressure $\sigma_{z}$ at $300 \mathrm{~K}$ (dashed curves, hollow symbols) and $600 \mathrm{~K}$ (solid curves, filled symbols) with linear or exponential fits to the data. Different symbol shapes and colors denote different compositions. At $600 \mathrm{~K}$, there is a normal pressure after which $\Delta \mathrm{GB}, \Delta \mathrm{TB}$, and $\left\langle d_{\text {shear }}\right\rangle$ saturate. Those data points were excluded from the respective fits to better capture the underlying trends. 

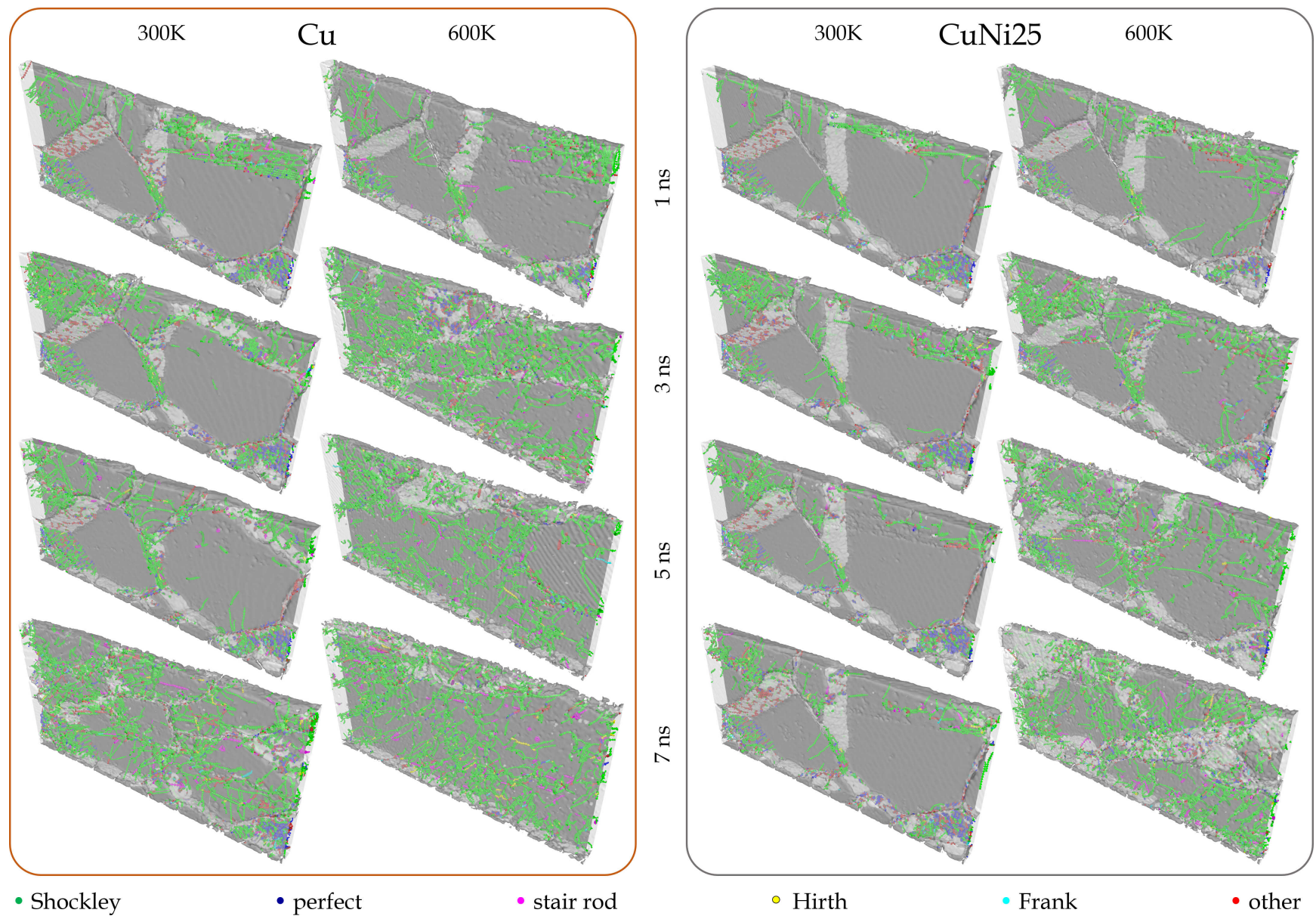

Figure 5. Time-resolved dislocation analysis at $0.4 \mathrm{GPa}$. Slab dimensions are $85 \mathrm{~nm} \times 40 \mathrm{~nm} \times 5 \mathrm{~nm}$. From left to right column: $\mathrm{Cu}$ at $300 \mathrm{~K}, \mathrm{Cu}$ at $600 \mathrm{~K}, \mathrm{CuNi} 25$ at $300 \mathrm{~K}, \mathrm{CuNi} 25$ at $600 \mathrm{~K}$. Coloring by dislocation type (green: Shockley, blue: perfect, magenta: stair rod, yellow: Hirth, cyan: Frank, red: other).

The obtained DXA results can be explained, at least qualitatively in the first instance, using the concept of stress-augmented thermal activation, first developed by Prandtl $[49,50]$ in the context of crystal plasticity and the origin of permanent plastic deformations. The expression he derived for the rate of plastic flow of a metal in terms of the effect of applied stress and temperature on the motion of atoms across the potential field of an adjacent atomic plane has set the scene for much of the work that now forms the basis for explaining not only dislocation activity in plastically deforming solids or frictional interfaces, but also the mechanisms governing tribochemical reactions, tribofilm formation, shear thinning, and phase transitions in viscous fluids [51-54].

Let us start by analyzing the results provided in Figure 2 looking at the implications that both the changes in stacking fault energy and temperature have on the system response. From an energetic point of view it is clear, as also demonstrated by the dislocation activity in Figure 5, that raising the Ni content within the binary alloy, therefore modifying the stacking fault energy, increases the energy barrier required to activate and promote dislocation activity. This corresponds to a decrease in the dislocation activity and in the extent of permanent deformations as well as transformations into the depth of the material with higher Ni content observed in our simulations. This is evident when comparing the results at the same temperature but for different alloys, with Figure 2 explicitly demonstrating the change in the onset and extent of permanent deformation under equivalent conditions, and Figure 5 showing quantitatively the reduction in dislocation activity for higher $\mathrm{Ni}$ content. The effect is local, where the modification of the activation energy barrier is linked to local changes in the deformation mechanisms at twin and grain boundaries, which is also visible in the concentration of dislocations at the GBs [55-57]. 
Turning now to the effect of temperature, this also significantly affects the activation energy; however, this time an increase in temperature corresponds to a decrease in activation energy, which is less localized and diffusion-driven. As a result, temperature variations produce the appearance of dislocation activity much further down the contact interface, this in turn favoring the earlier development of permanent deformations and a global downward shift of the response in terms of the applied stress required to observe transitions in the behavior of all the alloys studied in this investigation. Figure 5 clearly shows the appearance of a much larger density of, e.g., Shockley dislocations well distributed in specimens subjected to higher temperature when comparing the same microstructure and alloy compositions, clearly emphasizing the "diffusive" rather than "convective" nature of the effect that thermal energy has on the resistance of the alloy to sliding.

Delving into the specific dislocation mechanisms [58-60] that regulate the evolution of defects and interactions between dislocations, twins, and grain boundaries is certainly of interest, but it requires careful manipulation of a considerable quantity of data, which is outside the scope of the present contribution.

Our results obtained at $300 \mathrm{~K}$ and $600 \mathrm{~K}$ for all alloy compositions allow us to construct a 3D deformation mechanism map (Figure 6). The map correlates the influence of contact stress $\sigma_{z}$, Ni content, and homologous temperature with dominant interfacial deformation mechanisms, analogous to the procedure introduced for room temperature in [23]. The main difference is that the available data has been extended with MD simulations performed at $600 \mathrm{~K}$, which are displayed using an additional axis to include the homologous temperature $T / T_{m}$. The homologous temperature for each Ni concentration was obtained via linear interpolation between the values of $T_{m}$ for pure $\mathrm{Cu}$ and $\mathrm{Ni}$, which corresponds well to the solidus curve in the phase diagram [61]. The map illustrates that higher homologous temperatures reduce the threshold stress required for the transition to the next deformation regime with a higher degree of irreversible deformation, which in turn may correspond to more severe wear. At $600 \mathrm{~K}$, a higher Ni content is still beneficial for increasing the resistance to plastic deformation, even though there is a significant decrease in the threshold stress. The bottom right panel in Figure 6 shows the relative temperatureinduced reduction of the threshold stresses $\Delta \sigma_{\mathrm{th}}=\left(\sigma_{\mathrm{th}}^{(300 \mathrm{~K})}-\sigma_{\mathrm{th}}^{(600 \mathrm{~K})}\right) / \sigma_{\text {th }}^{(300 \mathrm{~K})}$ required for the transition from one deformation mechanism regime to the next as function of $\mathrm{Ni}$ content, where $\sigma_{\text {th }}$ denotes a threshold stress at a given temperature. The greatest composition dependence is found for the transition from the elastic to the twinning regime (solid blue curve), where the threshold stress is reduced by almost $70 \%$ for pure $\mathrm{Cu}$, but only by approximately $10 \%$ for $\mathrm{CuNi} 60$ and pure $\mathrm{Ni}$. This corresponds well to the fact that the latter two compositions are still below $0.4 \mathrm{~T} / \mathrm{T}_{m}$ at $600 \mathrm{~K}$. The other two transitions exhibit a similar trend, with the relative reductions of the threshold stresses in the range of $25-40 \%$ between pure $\mathrm{Ni}$ and pure $\mathrm{Cu}$ for the transition from twinning to grain refinement (dashed yellow curve), and a respective range of $35-45 \%$ for the transition from grain refinement to grain coarsening (dotted green curve). Note that the pronounced grain coarsening effect during sliding before the end of the simulation that is observed for pure $\mathrm{Cu}$ and visible in Figures 3 and 4 at normal pressures higher than $0.3 \mathrm{GPa}$ changes the dynamics of the system and therefore leads to the kink in the green and yellow curves, marking a slight decrease in $\sigma_{\text {th }}$ for pure $\mathrm{Cu}$. As with the first transition, the values for $\mathrm{CuNi60}$ and pure $\mathrm{Ni}$ are almost identical, since they are expected only to rise once the homologous temperature for a given composition exceeds 0.4 . 


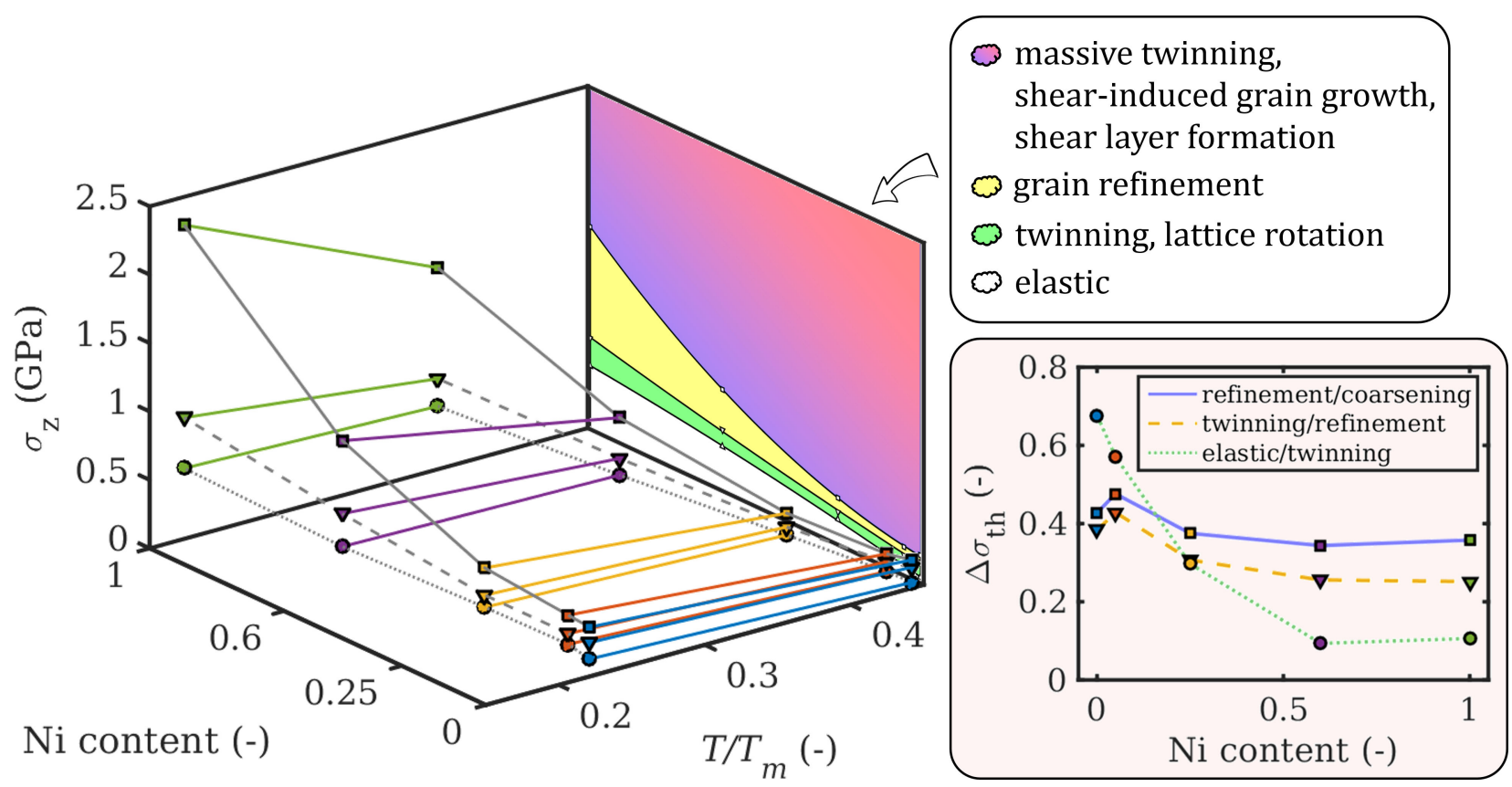

Figure 6. Threshold stresses $\sigma_{z}$ as a function of the homologous temperature and composition. Line colors denote compositions (same as above: $\mathrm{Cu}$ blue, Ni green). The gray lines connect the same type (=same symbol) of threshold stresses. Here, circles denote the upper boundary of the elastic regime, triangles of the twinning regime, and squares of the grain refinement regime. The map projected onto the back wall of the plot shows the distribution of the prevalent deformation mechanisms at $600 \mathrm{~K}$, named in the legend. The panel in the bottom right shows the relative reduction of the threshold stresses between deformation mechanism regimes due to the temperature increase from $300 \mathrm{~K}$ to $600 \mathrm{~K}$.

\section{Conclusions}

Understanding the link between microstructure and the friction and wear of materials undergoing contact and sliding is of paramount importance for tribological applications. Even more important is the understanding of the mechanisms and the synergies between factors that affect microstructural evolution and in turn the system response during operation, such as temperature, load, stacking fault energy, and grain size.

In this work, we used large-scale molecular dynamics simulations for the first time to explore the joint influence of temperature, applied load, and material composition on the tribological response of FCC alloys subjected to dry sliding against a rough surface. The paper systematically reveals the effects of temperature on well-defined key quantities, namely the fraction of GB and TB atoms, the shear layer thickness, and the sliding distance required for a sudden creation of defects, also considering the interplay with applied normal pressure and composition. This allows the following conclusions to be drawn:

- An increase in temperature from 300 to $600 \mathrm{~K}$ leads to a lowered energy barrier for defect activities and a larger extension of GBs and TBs into the depth.

- As the normal pressure increases, so do the differences between 300 and $600 \mathrm{~K}$ concerning the formation of $\mathrm{GB}$ and $\mathrm{TB}$ atoms.

- Additionally, higher temperature or lower $\mathrm{Ni}$ content facilitated the formation of a shear layer and significantly reduced the sliding distance required for a rapid increase in defect atoms, where higher temperatures in particular decrease this sliding distance by $20-50 \%$.

- When comparing pure copper with CuNi25, changes in the stacking fault energy lead to more localized effects at grain and twin boundaries, whereas higher temperature, which is associated with diffusive processes, results in dislocation densities being more evenly distributed than at higher stacking fault energies.

The considerations above were developed into a detailed 3D map for CuNi highlighting the dominating deformation regimes as a function of chemical composition, applied 
normal pressure, and homologous temperature. According to this map, higher homologous temperatures reduce the threshold stress required for the transition to the next deformation regime. With this knowledge, it is possible to obtain a better understanding of how alloys with a certain composition will react to an externally applied load under the effect of temperature, including permanent deformations and possible wear events. Thus, our results can serve as design guide to optimize alloy compositions for a wide range of applications where surfaces are subjected to sliding events at various operational temperatures. In particular, materials and coatings with optimized mechanical properties may, in the longer run, be applied to make jet engines safer, power plants more efficient, and oil production more sustainable.

Supplementary Materials: The following are available online at https:/ /www.mdpi.com/1996-194 4/14/1/60/s1, Figure S1: Time evolution of a representative EBSD tomographic section at constant normal pressure of $0.4 \mathrm{GPa}$. Figure S2: Time-resolved dislocation analysis at $0.4 \mathrm{GPa}$. Figure S3: Grain boundary and defect maps for Cu@600 K. Figure S4: Grain boundary and defect maps for CuNi5@600 K. Figure S5: Grain boundary and defect maps for CuNi2@600 K. Figure S6: Grain boundary and defect maps for CuNi60@600 K. Figure S7: Grain boundary and defect maps for Ni@600 K. Figure S8: Stress distribution maps for Cu@600 K. Figure S9: Stress distribution maps for CuNi5@600 K. Figure S10: Stress distribution maps for CuNi25@600 K. Figure S11: Stress distribution maps for CuNi60@600 K. Figure S12: Stress distribution maps for Ni@600 K. Figure S13: Grain boundary and defect fraction over time for $\mathrm{Cu}, \mathrm{CuNi} 5, \mathrm{CuNi} 25, \mathrm{CuNi60}$, and $\mathrm{Ni}$ when sliding at 600 K. Figure S14: Twin boundary and stacking fault fraction over time for $\mathrm{Cu}, \mathrm{CuNi5}, \mathrm{CuNi25}$, $\mathrm{CuNi60}$, and $\mathrm{Ni}$ when sliding at $600 \mathrm{~K}$. Figure S15: Shear layer thickness over time for $\mathrm{Cu}, \mathrm{CuNi}$, $\mathrm{CuNi25}$, CuNi60, and Ni when sliding at $600 \mathrm{~K}$. Figure S16: Refined layer thickness over time for $\mathrm{Cu}, \mathrm{CuNi5}, \mathrm{CuNi25}, \mathrm{CuNi60}$, and Ni when sliding at $600 \mathrm{~K}$. Figure S17: $\Delta$ GB over $\sigma_{z z}$ with linear fits at $600 \mathrm{~K}$. Figure S18: $\Delta$ TB over $\sigma_{z z}$ with linear fits at $600 \mathrm{~K}$. Figure S19: $\tau_{\text {crit }}$ over Ni content at $600 \mathrm{~K}$. Figure S20: $d_{\text {shear }}$ over $\sigma_{z z}$ at $600 \mathrm{~K}$, logarithmic scale. Figure S20: strans over $\sigma_{z z}$ at $600 \mathrm{~K}$, with exponential fit.

Author Contributions: Conceptualization, S.J.E. and C.G.; methodology, S.J.E.; software, S.J.E.; formal analysis, S.J.E.; investigation, S.J.E., P.G.G., M.R.R., D.D., and C.G.; resources, C.G.; data curation, S.J.E.; writing — original draft preparation, S.J.E., P.G.G., M.R.R., D.D., and C.G.; visualization, S.J.E.; supervision, D.D. and C.G. All authors have read and agreed to the published version of the manuscript.

Funding: Part of this work was supported by the Austrian COMET-Program (K2 Project InTribology, no. 872176) and carried out at the "Excellence Centre of Tribology" (AC2T research GmbH). The government of Lower Austria supported the endowed professorship tribology at the TU Vienna (grant no. WST3-F-5031370/001-2017). D.D. acknowledges the support of the Engineering and Physical Sciences Research Council (EPSRC) via his Established Career Fellowship EP/N025954/1. The computational results presented have been achieved using the Vienna Scientific Cluster (VSC). Open Access Funding by TU Wien.

Institutional Review Board Statement: Not applicable.

Informed Consent Statement: Not applicable.

Data Availability Statement: The data presented in this study are available on request from the corresponding author.

Conflicts of Interest: The authors declare no conflict of interest. The funders had no role in the design of the study; in the collection, analyses, or interpretation of data; in the writing of the manuscript, or in the decision to publish the results. 


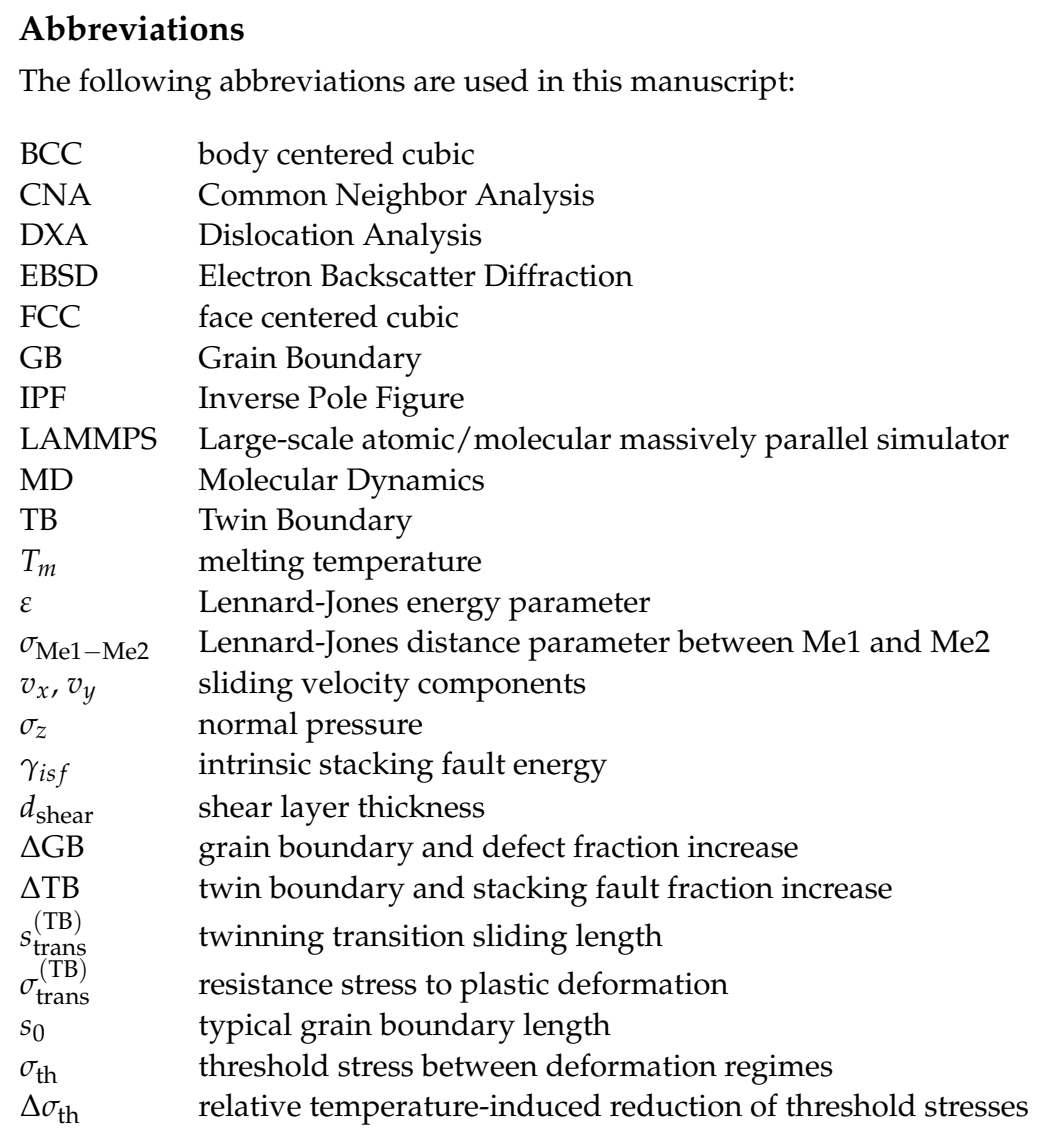

\section{References}

1. Li, A.; Szlufarska, I. How grain size controls friction and wear in nanocrystalline metals. Phys. Rev. B 2015, 92, 075418. [CrossRef]

2. Prasad, S.V.; Battaile, C.C.; Kotula, P.G. Friction transitions in nanocrystalline nickel. Scr. Mater. 2011, 64, 729-732. [CrossRef]

3. Argibay, N.; Chandross, M.; Cheng, S.; Michael, J.R. Linking microstructural evolution and macro-scale friction behavior in metals. J. Mater. Sci. 2017, 52, 2780-2799. [CrossRef]

4. Farhat, Z.; Ding, Y.; Northwood, D.; Alpas, A. Effect of grain size on friction and wear of nanocrystalline aluminum. Mater. Sci. Eng. A 1996, 206, 302-313. [CrossRef]

5. Rupert, T.J.; Schuh, C.A. Sliding wear of nanocrystalline Ni-W: Structural evolution and the apparent breakdown of Archard scaling. Acta Mater. 2010, 58, 4137-4148. [CrossRef]

6. Greiner, C.; Gagel, J.; Gumbsch, P. Solids Under Extreme Shear: Friction-Mediated Subsurface Structural Transformations. Adv. Mater. 2019, 31, 1806705. [CrossRef]

7. Greiner, C.; Liu, Z.; Schneider, R.; Pastewka, L.; Gumbsch, P. The origin of surface microstructure evolution in sliding friction. Scr. Mater. 2018, 153, 63-67. [CrossRef]

8. Rogers, S.R.; Bowden, D.; Unnikrishnan, R.; Scenini, F.; Preuss, M.; Stewart, D.; Dini, D.; Dye, D. The interaction of galling and oxidation in 316L stainless steel. Wear 2020, 450, 203234. [CrossRef]

9. Grützmacher, P.G.; Rammacher, S.; Rathmann, D.; Motz, C.; Mücklich, F.; Suarez, S. Interplay between microstructural evolution and tribo-chemistry during dry sliding of metals. Friction 2019, 7, 637-650. [CrossRef]

10. Rosenkranz, A.; Grützmacher, P.G.; Gachot, C.; Costa, H.L. Surface texturing in machine elements-A critical discussion for rolling and sliding contacts. Adv. Eng. Mater. 2019, 21, 1900194. [CrossRef]

11. Bustillo, A.; Pimenov, D.Y.; Matuszewski, M.; Mikolajczyk, T. Using artificial intelligence models for the prediction of surface wear based on surface isotropy levels. Robot. Comput.-Integr. Manuf. 2018, 53, 215-227. [CrossRef]

12. Pauschitz, A.; Roy, M.; Franek, F. Mechanisms of sliding wear of metals and alloys at elevated temperatures. Tribol. Int. 2008, 41, 584-602. [CrossRef]

13. Priest, M.; Taylor, C.M. Automobile engine tribology-Approaching the surface. Wear 2000, 241, 193-203. [CrossRef]

14. Tung, S.C.; McMillan, M.L. Automotive tribology overview of current advances and challenges for the future. Tribol. Int. 2004, 37, 517-536. [CrossRef]

15. Stoyanov, P.; Harrington, K.M.; Frye, A. Insights into the Tribological Characteristic of Cu-Based Coatings Under Extreme Contact Conditions. JOM 2020, 72, 2191-2197. [CrossRef]

16. Zhang, Z.; Dong, H. A State-of-the-art overview-Recent development in low friction and wear-resistant coatings and surfaces for high-temperature forming tools. Manuf. Rev. 2014, 1, 24. 
17. Torres, H.; Varga, M.; Ripoll, M.R. High temperature hardness of steels and iron-based alloys. Mater. Sci. Eng. A 2016, 671, 170-181. [CrossRef]

18. Frost, H.J.; Ashby, M.F. Deformation Mechanism Maps: The Plasticity and Creep of Metals and Ceramics; Pergamon Press: Oxford, UK, 1982.

19. Hasnaoui, A.; Van Swygenhoven, H.; Derlet, P. Cooperative processes during plastic deformation in nanocrystalline fcc metals: A molecular dynamics simulation. Phys. Rev. B 2002, 66, 184112. [CrossRef]

20. Van Swygenhoven, H.; Derlet, P.; Frøseth, A. Stacking fault energies and slip in nanocrystalline metals. Nat. Mater. 2004, 3, 399-403. [CrossRef]

21. Yamakov, V.; Wolf, D.; Phillpot, S.; Mukherjee, A.; Gleiter, H. Deformation-mechanism map for nanocrystalline metals by molecular-dynamics simulation. Nat. Mater. 2004, 3, 43-47. [CrossRef]

22. Tadmor, E.B.; Miller, R.E. Modeling Materials: Continuum, Atomistic and Multiscale Techniques; Cambridge University Press: Cambridge, UK, 2011.

23. Eder, S.J.; Rodríguez Ripoll, M.; Cihak-Bayr, U.; Dini, D.; Gachot, C. Unraveling and Mapping the Mechanisms for Near-surface Microstructure Evolution in CuNi Alloys under Sliding. ACS Appl. Mater. Interfaces 2020, 12, 32197-32208. [CrossRef] [PubMed]

24. Eder, S.J.; Leroch, S.; Grützmacher, P.; Spenger, T.; Heckes, H. A multiscale simulation approach to grinding ferrous surfaces for process optimization. Int. J. Mech. Sci. 2021, 194, 106186. [CrossRef]

25. Romero, P.A.; Järvi, T.T.; Beckmann, N.; Mrovec, M.; Moseler, M. Coarse graining and localized plasticity between sliding nanocrystalline metals. Phys. Rev. Lett. 2014, 113, 036101. [CrossRef] [PubMed]

26. Eder, S.J.; Cihak-Bayr, U.; Bianchi, D. Single-asperity contributions to multi-asperity wear simulated with molecular dynamics. IOP Conf. Ser. Mater. Sci. Eng. 2016, 119, 012009. [CrossRef]

27. Jacobs, T.D.; Greiner, C.; Wahl, K.J.; Carpick, R.W. Insights into tribology from in situ nanoscale experiments. MRS Bull. 2019, 44, 478-486. [CrossRef]

28. Powell, C.A.; Michels, H.T. Copper-nickel alloys for seawater corrosion resistance and anti-fouling: A state of the art review. In Proceedings of the CORROSION 2000, Orlando, FL, USA, 26-31 March 2000; NACE International: Houston, TX, USA, 2000.

29. Noguchi, M. Sliding Member, Rotary Device, and Method for Manufacturing Sliding Member. US Patent 10,505,328, 10 December 2019.

30. Bonny, G.; Pasianot, R.C.; Castin, N.; Malerba, L. Ternary Fe-Cu-Ni many-body potential to model reactor pressure vessel steels: First validation by simulated thermal annealing. Philos. Mag. 2009, 89, 3531-3546. [CrossRef]

31. Eder, S.J.; Cihak-Bayr, U.; Bianchi, D.; Feldbauer, G.; Betz, G. Thermostat Influence on the Structural Development and Material Removal during Abrasion of Nanocrystalline Ferrite. ACS Appl. Mater. Interfaces 2017, 9, 13713-13725, [CrossRef]

32. Plimpton, S.J. Fast parallel algorithms for short-range molecular dynamics. J. Comput. Phys. 1995, 117, 1-19. [CrossRef]

33. Eder, S.J.; Bianchi, D.; Cihak-Bayr, U.; Gkagkas, K. Methods for atomistic abrasion simulations of laterally periodic polycrystalline substrates with fractal surfaces. Comput. Phys. Commun. 2017, 212, 100-112, [CrossRef]

34. Eder, S.J.; Cihak-Bayr, U.; Gachot, C.; Rodríguez Ripoll, M. Interfacial Microstructure Evolution Due to Strain Path Changes in Sliding Contacts. ACS Appl. Mater. Interfaces 2018, 10, 24288-24301. [CrossRef]

35. Ewen, J.P.; Restrepo, S.E.; Morgan, N.; Dini, D. Nonequilibrium molecular dynamics simulations of stearic acid adsorbed on iron surfaces with nanoscale roughness. Tribol. Int. 2017, 107, 264-273. [CrossRef]

36. Eder, S.J.; Cihak-Bayr, U.; Vernes, A.; Betz, G. Evolution of topography and material removal during nanoscale grinding. J. Phys. D Appl. Phys. 2015, 48, 465308, [CrossRef]

37. Li, W.; Lu, S.; Hu, Q.M.; Kwon, S.K.; Johansson, B.; Vitos, L. Generalized stacking fault energies of alloys. J. Phys. Condens. Matter 2014, 26, 265005. [CrossRef] [PubMed]

38. Larsen, P.M.; Schmidt, S.; Schiøtz, J. Robust structural identification via polyhedral template matching. Model. Simul. Mater. Sci. Eng. 2016, 24, 055007. [CrossRef]

39. Stukowski, A. Visualization and analysis of atomistic simulation data with OVITO-The Open Visualization Tool. Model. Simul. Mater. Sci. Eng. 2009, 18, 015012. [CrossRef]

40. Bachmann, F.; Hielscher, R.; Schaeben, H. Texture analysis with MTEX-Free and open source software toolbox. Solid State Phenom. 2010, 160, 63-68. [CrossRef]

41. Nolze, G.; Hielscher, R. Orientations-perfectly colored. J. Appl. Crystallogr. 2016, 49, 1786-1802. [CrossRef]

42. Stukowski, A.; Bulatov, V.V.; Arsenlis, A. Automated identification and indexing of dislocations in crystal interfaces. Model. Simul. Mater. Sci. Eng. 2012, 20, 085007. [CrossRef]

43. Tsuzuki, H.; Branicio, P.S.; Rino, J.P. Structural characterization of deformed crystals by analysis of common atomic neighborhood. Comput. Phys. Commun. 2007, 177, 518-523. [CrossRef]

44. Eder, S.J.; Cihak-Bayr, U.; Bianchi, D. Large-scale molecular dynamics simulations of nanomachining. In Advanced Machining Processes: Innovative Modeling Techniques; CRC Press: Boca Raton, FL, USA, 2017; p. 141.

45. Chen, X.; Schneider, R.; Gumbsch, P.; Greiner, C. Microstructure evolution and deformation mechanisms during high rate and cryogenic sliding of copper. Acta Mater. 2018, 161, 138-149. [CrossRef]

46. Meyers, M.A.; Mishra, A.; Benson, D.J. Mechanical properties of nanocrystalline materials. Prog. Mater. Sci. 2006, 51, 427-556. [CrossRef] 
47. Grützmacher, P.; Gachot, C.; Eder, S.J. Visualization of microstructural mechanisms in nanocrystalline ferrite during grinding. Mater. Des. 2020, 195, 109053.

48. Meyers, M.; Vöhringer, O.; Lubarda, V. The onset of twinning in metals: A constitutive description. Acta Mater. 2001, 49, 4025-4039. [CrossRef]

49. Prandtl, L. Ein Gedankenmodell zur kinetischen Theorie der festen Körper. ZAMM-J. Appl. Math. Mech./Z. Angew. Math. Mech. 1928, 8, 85-106. [CrossRef]

50. Spikes, H. Stress-augmented thermal activation: Tribology feels the force. Friction 2018, 6, 1-31. [CrossRef]

51. Gosvami, N.; Bares, J.; Mangolini, F.; Konicek, A.; Yablon, D.; Carpick, R. Mechanisms of antiwear tribofilm growth revealed in situ by single-asperity sliding contacts. Science 2015, 348, 102-106. [CrossRef]

52. Yeon, J.; He, X.; Martini, A.; Kim, S.H. Mechanochemistry at solid surfaces: Polymerization of adsorbed molecules by mechanical shear at tribological interfaces. ACS Appl. Mater. Interfaces 2017, 9, 3142-3148. [CrossRef]

53. Martini, A.; Eder, S.J.; Dörr, N. Tribochemistry: A Review of Reactive Molecular Dynamics Simulations. Lubricants 2020, 8, 44. [CrossRef]

54. Spikes, H.; Tysoe, W. On the commonality between theoretical models for fluid and solid friction, wear and tribochemistry. Tribol. Lett. 2015, 59, 21. [CrossRef]

55. Bouaziz, O.; Allain, S.; Scott, C. Effect of grain and twin boundaries on the hardening mechanisms of twinning-induced plasticity steels. Scr. Mater. 2008, 58, 484-487. [CrossRef]

56. Wu, Z.; Zhang, Y.; Srolovitz, D. Deformation mechanisms, length scales and optimizing the mechanical properties of nanotwinned metals. Acta Mater. 2011, 59, 6890-6900. [CrossRef]

57. Tucker, G.J.; Foiles, S.M. Quantifying the influence of twin boundaries on the deformation of nanocrystalline copper using atomistic simulations. Int. J. Plast. 2015, 65, 191-205. [CrossRef]

58. Gumbsch, P.; Gao, H. Dislocations faster than the speed of sound. Science 1999, 283, 965-968. [CrossRef] [PubMed]

59. Borovikov, V.; Mendelev, M.I.; King, A.H.; LeSar, R. Effect of stacking fault energy on mechanism of plastic deformation in nanotwinned FCC metals. Model. Simul. Mater. Sci. Eng. 2015, 23, 055003. [CrossRef]

60. Gurrutxaga-Lerma, B.; Verschueren, J.; Sutton, A.P.; Dini, D. The mechanics and physics of high-speed dislocations: A critical review. Int. Mater. Rev. 2020, 1-41. [CrossRef]

61. Westbrook, J.; Fleischer, R. Structural Applications of Intermetallic Compounds; Wiley: Hoboken, NJ, USA, 2000 ; Volume 3. 